\title{
Short- and Long-Term Reduction of Door-to-Needle Time in Thrombolysis for Acute Stroke
}

\author{
Bing Yu Chen, Aimen Moussaddy, Mark R. Keezer, Yan Deschaintre, \\ Alexandre Y. Poppe
}

\begin{abstract}
Background: More timely administration of tissue plasminogen activator (alteplase) for patients with acute ischemic stroke yields greater clinical benefits. We implemented door-to-needle (DTN) time reduction strategies at our center and evaluated their short- and long-term effects on in-hospital treatment delays and clinical outcomes. Methods: Strategies, including stroke team prenotification, direct computed tomography transfer, not routinely waiting for laboratory results and alteplase delivery on the computed tomography table, were implemented in June 2013. We included all thrombolysed patients admitted directly to our hospital between January 2012 and March 2015. In-hospital delays and symptomatic intracerebral hemorrhage rates were compared between patients preand postmodification, and the latter period was divided into early (first 6 months) and late (beyond 6 months) phases to assess the durability of our modifications. Results: Forty-eight individuals were treated premodification compared with 58 postmodification. The median DTN time was reduced from 75 to 46 minutes $(\mathrm{p}<0.0001)$. The median DTN time in the early and late postmodification phases was not significantly different ( 41 vs 46 minutes, $p=0.4085$ ). There was no significant difference in rates of symptomatic intracerebral hemorrhage (4.2 vs $1.7 \%, p=0.361)$ or stroke mimics $(2.1$ ves $5.2 \%, p=0.625)$ Conclusions: We were able to decrease our DTN time for acute stroke thrombolysis by implementing relatively simple modifications and these improvements persisted over time.
\end{abstract}

RÉSUMÉ: Réduction à court terme et à long terme des délais « porte-aiguille » de traitements thrombolytiques à la suite d'AVC aigus. Contexte: L'administration dans des délais convenables d'un activateur tissulaire du plasminogène (l'altéplase) à des patients victimes d'un AVC ischémique aigu entraîne de meilleures retombées cliniques. À cet égard, nous avons mis en œuvre dans notre établissement des stratégies de réduction des délais « porteaiguille » (door-to-needle) et aussi évalué leurs effets à court terme et à long terme en ce qui regarde les délais de traitement hospitalier et leurs résultats cliniques. Méthodes: Nos stratégies ont été mises en œuvre en juin 2013 et ont consisté notamment à : donner un préavis à l'équipe de traitements des AVC ; à transmettre directement les résultats de tomodensitométrie ; à ne pas systématiquement attendre les résultats de laboratoire ; et à faire livrer l'altéplase au moment de procéder à un examen tomodensitométrique. Nous avons par ailleurs inclus dans cette étude tous les patients thrombolysés ayant été admis directement dans notre hôpital entre janvier 2012 et mars 2015. Les patients traités avant la mise en œuvre de nos stratégies et ceux l'ayant été après cette mise en œuvre ont été comparés en ce qui a trait à leurs périodes d'hospitalisation et leurs taux d'hémorragie intracérébrale symptomatique. La période de mise en œuvre a ensuite été divisée entre les 6 premiers mois et les 6 autres mois suivants afin d'évaluer la pérennité des améliorations induites. Résultats: Quarante-huit patients ont été traités avant que nous mettions en œuvre nos stratégies alors que 58 autres l'ont été une fois ces stratégies mises en œuvre. Les délais médians « porte-aiguille» sont passés de 75 à 46 minutes $(\mathrm{p}<0,0001)$. De plus, ces mêmes délais ne sont pas apparus sensiblement différents au début ou plus tard lors de notre période de mise en œuvre ( $41 \mathrm{~min}$ contre $46 \mathrm{~min} ; \mathrm{p}=0,4085$ ). Aucune différence notable n'a été non plus observée en ce qui regarde les taux d'hémorragie intracérébrale symptomatique $(4,2 \%$ contre $1,7 \% ; p=0,361)$ ou l'occurrence d'affections imitant les symptômes de l'AVC (stroke mimics) $(2,1 \%$ contre 5,2\%; p=0,625). Conclusions: Nous avons été en mesure de diminuer les délais «porte-aiguille » liés au traitement thrombolytique d'AVC aigus en mettant en œuvre des améliorations relativement simples. Fait à noter, ces améliorations ont persisté au fil du temps.

Key words: stroke, thrombolysis, acute stroke, ischemic brain injury

doi:10.1017/cjn.2016.416

Can J Neurol Sci. 2017; 44: 255-260

Intravenous administration of tissue plasminogen activator (alteplase) is the primary treatment of acute ischemic stroke in eligible patients. ${ }^{1,2}$ Clinical benefits of stroke thrombolysis depend on the timeliness of alteplase bolus delivery, and earlier treatment has been shown to reduce long-term functional disability, in-hospital mortality, and symptomatic intracranial hemorrhage, and to lower the risk of other medical complications. ${ }^{3}$ Thrombolysis is most effective within 90 minutes of onset-to-needle (OTN) time, ${ }^{4}$ and

From the Faculty of Medicine, McGill University, Montréal, Québec, Canada (BYC); Department of Neurosciences, Université de Montréal, Centre Hospitalier de l'Université de

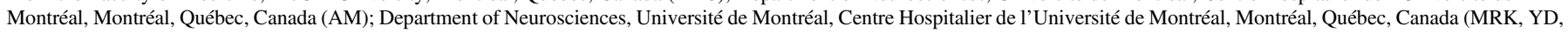

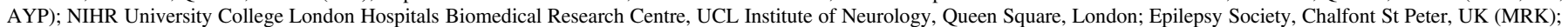
Stichting Epilepsie Instellingen Nederland, Heemstede, The Netherlands (MRK)

Received May 27, 2016. Final Revisions Submitted October 10, 2016. Date of Acceptance November 6, 2016.

Address correspondence to: Alexandre Y. Poppe, Department of Neurosciences, Université de Montréal, Centre Hospitalier de l'Université de Montréal, Hôpital Notre-Dame, 1560 Sherbrooke East, Montreal, Quebec, Canada, H2L 4M1. Email: alexandre.yves.poppe@umontreal.ca 
there is no evidence of benefit beyond 4.5 hours after symptom onset. ${ }^{5}$ Reducing the door-to-needle (DTN) time is therefore an essential objective in optimizing hyperacute stroke care.

Interventions aimed at minimizing stroke thrombolysis delays have been suggested in numerous publications, ${ }^{6-10}$ one of which reported that DTN time was nearly halved following protocol changes. ${ }^{11}$ Among the most cited strategies are stroke team prenotification by emergency medical services (EMS), rapid head computed tomography (CT) scan acquisition and alteplase delivery on the CT table. ${ }^{11}$ In most of these studies, quality improvement modifications were implemented over a relatively long period, and the long-term persistence of these modifications on DTN time was not presented.

To conform to Canadian guidelines recommending a DTN of $\leq 60$ minutes, ${ }^{12}$ we implemented some of the most cited DTN time reduction strategies in our acute stroke protocol. To rapidly offer the recommended delays to our patients, these modifications were all applied within 1 month. The primary objective of this qualityimprovement, single-center study was to assess the short- and long-term effects of these modifications on our median DTN times and the proportion of patients receiving intravenous alteplase within 60 minutes. Our secondary objective was to compare stroke mimic and symptomatic intracerebral hemorrhage (sICH) rates in both study phases.

\section{METHODS}

\section{Health Care Setting}

Canada covers most medical services including acute stroke care through a publicly funded health insurance program. During the period covered in this study, in the province of Quebec, EMS transported patients to the nearest hospital and, if necessary, subsequently transferred them to a tertiary center for more specialized treatment such as intravenous alteplase. Notre-Dame Hospital (Centre Hospitalier de l'Université de Montréal) is a tertiary academic center offering thrombolysis to patients residing in the greater Montreal area and parts of the north and south shores of the island-city (with a catchment of approximately 1.5 million inhabitants).

\section{Participants}

This study used a prospective registry of consecutive thrombolyzed ischemic stroke patients admitted to Notre-Dame Hospital since 2001. From this registry, we included patients admitted directly to our hospital between January 2012 and March 2015, and excluded individuals transferred from our hospital's inpatient units or from other hospitals. There was no registry for nonthrombolyzed individuals. Included patients were categorized, based on the date of the stroke event, into the premodification phase (January 1, 2012-May 31, 2013) and the postmodification phase (July 1, 2013-March 31, 2015). June 1 to 30, 2013, constituted the implementation and transition phase. To separate the short- from the long-term effects of our interventions and assess the durability of our quality improvement initiative, the postmodification phase was subdivided into the early postmodification phase (July 1, 2013-December 31, 2013) and the late postmodification phase (January 1, 2014-March 31, 2015). We obtained institutional ethics review board approval to maintain the registry and to conduct this study.

\section{Premodification Hyperacute Stroke Care Model}

Until May 2013, rapid notification to the stroke team via a singlecall activation system (stroke pager) was enabled by the emergency department (ED) physician after initial assessment of the patient presenting with stroke symptoms. A stroke toolkit was available in the ED and included preprinted CT and laboratory order sets. Approach to care included the following: a system of parallel patient history-taking and neurological evaluation by the resident and neurologist during transport to the CT room, patient blood-drawing upon admission, priority access to standard stat laboratory testing for quick results before treatment, and head CT scan evaluation by stroke neurologist without waiting for radiology report. Stroke patients were followed 3 months postdischarge as part of routine care.

\section{Postmodification Hyperacute Stroke Care Model}

In 2013, we completed a quality assessment of the previous model and developed a new model aimed at achieving a median DTN time of $\leq 60$ minutes. Literature describing strategies to improve in-hospital treatment delays were reviewed and locally applicable models were retained. A working group of stroke neurologists, neurology residents, stroke nurses, neuroradiologists, and emergency physicians discussed the feasibility of these strategies and agreed on a restructured management algorithm.

The following changes were made over the course of 1 month: EMS prenotified triage, which immediately alerted the stroke team before EMS hospital arrival via a single-call activation system upon prehospital suspicion of stroke; laboratory results other than a capillary blood glucose level were not waited on to make treatment decisions (except in specific clinical scenarios such as known anticoagulation); the patient was directly transferred from EMS to CT table upon arrival instead; a dedicated key granted access to reserved elevators for faster transfer to CT scan; an inhouse radiology technician was made available 24/7; alteplase bolus was administered on the CT table after plain CT; and, in addition to regular informal feedback, treatment delays for all patient were posted in the hyperacute stroke care area to allow direct feedback team-member validation. Table 1 compares strategies used in the pre- and postmodification models.

\section{Statistical Analysis}

To complete missing data from our prospective registry, medical records were hand-searched to extract date of stroke admission, age, gender, stroke etiology (Trial of Org. 10172 in Acute Stroke Treatment classification), ${ }^{13}$ National Institutes of Health Stroke Scale (NIHSS, 0-42 score range, lower is better) on stroke admission, use of CT angiography (CTA), and symptomatic intracranial hemorrhage (sICH, third European Cooperative Acute Stroke Study definition ${ }^{14}$ ). Delays were calculated by subtraction and refer to the onset-to-door time (delay between stroke onset and hospital arrival), head CT completion delay time (delay between hospital arrival and first head CT), DTN time (delay between hospital arrival and alteplase bolus administration), and OTN time (delay between stroke onset or last known well time and alteplase bolus administration).

Medians (interquartile range $[\mathrm{IQR}]$ ) are presented for continuous variables with the assumption that their distributions are skewed. Comparisons across continuous variables were carried out using the Wilcoxon rank-sum and Kruskal-Wallis tests. 
Table 1: Hyperacute stroke care models during the pre- and postmodification phases (changes in bold type)

\begin{tabular}{|c|c|c|}
\hline Step & Premodification phase & Postmodification phase \\
\hline Notification & $\begin{array}{l}\text { - Initial patient assessment by ED } \\
\text { - Notification of stroke team by ED via single-call activation system } \\
\text { (stroke pager) }\end{array}$ & - Prenotification of stroke team by EMS via single-call activation system \\
\hline Stroke toolkit & - Preprinted CT and laboratory order sets & - Preprinted CT and laboratory order sets \\
\hline Medical history & $\begin{array}{l}\text { - Parallel history-taking and neurological evaluation by resident and } \\
\text { neurologist }\end{array}$ & - Parallel history-taking and neurological evaluation by resident and neurologist \\
\hline Laboratory tests & - Priority access to standard stat laboratory testing & $\begin{array}{l}\text { - Priority access to point-of-care glycemia measurement } \\
\text { - INR only used if anticoagulation suspected }\end{array}$ \\
\hline Transfer to CT & - Transfer from EMS to ED bed upon hospital arrival, then to CT & $\begin{array}{l}\text { - Direct transfer from EMS to CT upon hospital arrival } \\
\text { - Reserved access to elevator }\end{array}$ \\
\hline CT scan & $\begin{array}{l}\text { - CT scan interpreted by stroke neurologist without waiting for } \\
\text { radiology report }\end{array}$ & $\begin{array}{l}\text { - CT technician available } 24 / 7 \text { and directly accessible by stroke team } \\
\text { - CT scan interpreted by stroke neurologist without waiting for radiology report }\end{array}$ \\
\hline Alteplase delivery & - Upon return to ED bed & - On CT table \\
\hline Feedback & - Irregular informal feedback & $\begin{array}{l}\text { - Regular feedback to nursing and radiology personnel } \\
\text { - Posting of DTN times for personnel to see }\end{array}$ \\
\hline
\end{tabular}

CT, computed tomography; ED, emergency department; EMS, emergency medical services; INR, international normalized ratio; tPA, tissue plasminogen activator.

Pearson chi-squared test was generally used to compare proportions. For the comparison of the probability of stroke mimics, Fisher exact test was used because of small sample sizes. Statistical significance was defined as a $\mathrm{p}$ value $<0.05$ (two-tailed). We used multiple linear regression models to assess for covariates of continuous outcomes and Poisson regression with robust variance for categorical outcomes. Independent variables included in each model, chosen based on their perceived clinical and biological relevance, were gender, age, OTN time, admission NIHSS score, and study group (dichotomized into pre- and postmodification). In the face of missing values, we carried out complete case analyses. The distribution of residuals was confirmed for each multiple linear regression, and goodness of fit was confirmed for each Poisson regression. Statistical analyses were carried out using STATA/SE, version 12.0 (StataCorp LP, College Station, TX).

\section{Results}

\section{Baseline Clinical Characteristics}

The clinical characteristics of the patient population treated between 2012 and 2015 are shown in Table 2. Forty-eight individuals (median age, 75 years; $58.3 \%$ female), were thrombolyzed from January 2012 to May 2013 (premodification phase). Fifty-eight patients (median age, 76 years; $41.4 \%$ female) were treated between July 2013 and March 2015 (postmodification phase). Twenty of these were treated between July and December 2013 (early postmodification phase), and 38 between January 2014 and March 2015 (late postmodification phase). There was no difference in median admission NIHSS 12 (IQR 9-18) versus 13 (IQR 7-20) $(\mathrm{p}=0.841)$.

\section{In-Hospital Treatment Delays}

As shown in Table 3, median delay to head CT decreased from 25 minutes to 19 minutes $(\mathrm{p}=0.0204)$. There was a nonsignificant trend toward more frequent use of CTA, from $52.1 \%$ to $69.0 \%$ $(\mathrm{p}=0.076)$.

Median DTN time decreased from 75 to 46 minutes between the pre- and postmodification phases $(\mathrm{p}<0.0001)$; no change in DTN time was found between the early and late postmodification phases $(p=0.4085)$. The proportion of patients treated within 60 minutes also increased in the postmodification phase, from $29.2 \%$ to $75.9 \%(p<0.001)$, and this remained unchanged between the early and late postmodification phase $(\mathrm{p}=0.161)$ (Figure 1). There was a nonsignificant trend toward decreased OTN times between the pre- and post- phases, at 151 minutes versus 130 minutes $(p=0.0895)$. The proportion of patients treated within 90 minutes of stroke onset improved $(2.1 \%$ vs $19.0 \%$, $\mathrm{p}=0.006$ ) but remained quite low in both phases (Figure 2). The reduction in OTN times was sustained during the early and late postmodification phases $(\mathrm{p}=0.395)$.

\section{Stroke Mimic and sICH Rates}

Symptomatic ICH (4.2 vs $1.7 \%, \mathrm{p}=0.361)$ and stroke mimic rates $(2.1 \mathrm{vs} 5.2 \%, \mathrm{p}=0.625)$ rates were no different between the pre- and postmodification phases.

\section{DISCUSSION}

Our aim was to implement DTN time reduction strategies in our center relatively quickly, to determine whether reductions were achieved, and whether these were durable over time. We showed that it was possible to implement multiple simple interventions in a very short timeframe with no additional financial investment. The median DTN time was significantly shortened from 75 minutes to 46 minutes. This improvement occurred quickly, reaching 41 minutes over the first 6 months and remaining stable over the ensuing months at 46 minutes. The proportion of patients treated within the recommended delays of 60 minutes $^{12}$ nearly tripled, from $29.2 \%$ to $75.9 \%$, whereas the 
Table 2: Baseline characteristics of patient population

\begin{tabular}{|c|c|c|c|c|c|c|}
\hline & & \multirow[b]{2}{*}{ Premodification } & \multicolumn{3}{|c|}{ Postmodification } & \multirow[b]{3}{*}{$P$ value $^{\dagger}$} \\
\hline & & & Overall" & Early & Late & \\
\hline \multicolumn{2}{|l|}{ Number of patients } & 48 & 58 & 20 & 38 & \\
\hline \multicolumn{2}{|l|}{ Age, years } & $75(66-80)$ & $76(63-83)$ & $79(67-86)$ & $74(56-83)$ & \\
\hline \multicolumn{2}{|l|}{ Female, $\%$} & 58.3 & 41.4 & 45.0 & 39.5 & \\
\hline \multirow[t]{6}{*}{ Stroke etiology, $\%$} & Large artery atherosclerosis & 18.8 & 24.1 & 20.0 & 26.3 & 0.111 \\
\hline & Cardioembolism & 31.3 & 37.9 & 30.0 & 42.1 & \\
\hline & Small vessel occlusion & 2.1 & 6.9 & 10.0 & 5.3 & \\
\hline & Stroke of other determined etiology & 0.0 & 5.2 & 10.0 & 2.6 & \\
\hline & Stroke of undetermined etiology & 20.8 & 8.6 & 5.0 & 10.5 & \\
\hline & Undocumented & 25.0 & 12.1 & 25.0 & 5.3 & \\
\hline \multicolumn{2}{|c|}{ NIHSS on stroke admission } & $12(9-18)$ & $13(7-20)$ & $11(6-19)$ & $13(7-21)$ & 0.841 \\
\hline \multicolumn{2}{|c|}{ Onset-to-door time, minutes } & $67(52-89)$ & $74(51-126)$ & $81(50-123)$ & $71(51-126)$ & 0.428 \\
\hline
\end{tabular}

NIHSS $=$ National Institutes of Health Stroke Scale.

Values expressed in median (interquartile range) or percentage.

*Overall refers to early and late combined.

The statistical tests compared premodification phase to overall postmodification phase.

number of patients benefiting from treatment within 90 minutes of onset increased ninefold, from $2.1 \%$ to $19.0 \%$. Both of these effects were durable. This reduction in treatment times has already been shown in larger cohorts to confer improved clinical and functional outcomes for patients. ${ }^{3}$

Several evidence-based interventions were studied in the conception of our new model, ${ }^{6-10,15}$ and we opted for simultaneous implementation of the strategies most applicable to our milieu. Stroke pager notification by ED physician ensures that the stroke team arrives quickly when an acute stroke is suspected. ${ }^{16,17}$
However, stroke team prenotification by the triage nurse enables the stroke physician to begin assessing the patient almost immediately upon ED arrival. Although not shown in our results, others have noted that this strategy is a key driver in DTN time reduction. ${ }^{18,19}$ Multiple changes were aimed at shortening the delay from arrival to head imaging, such as direct transfer from EMS stretcher to CT and reserved access to elevators. To mitigate prolonged delays during off-hours, ${ }^{11}$ we introduced $24 / 7$ CT technician availability. Commensurate with changing practices, the proportion of patients undergoing CTA increased from $52.1 \%$

Table 3: Imaging and treatment times, symptomatic ICH, and stroke mimic rates during the pre- and postmodification phases

\begin{tabular}{|c|c|c|c|c|c|c|c|}
\hline & \multirow[b]{2}{*}{ Premodification } & \multicolumn{3}{|c|}{ Postmodification } & \multicolumn{3}{|c|}{$P$ value } \\
\hline & & Overall $^{*}$ & Early & Late & $\begin{array}{l}\text { Pre, early post, } \\
\text { late post }^{\dagger}\end{array}$ & Pre, post ${ }^{\ddagger}$ & $\begin{array}{l}\text { Early post, } \\
\text { late post }\end{array}$ \\
\hline Number of patients & 48 & 58 & 20 & 38 & & & \\
\hline Transfer to head CT scan delay time, minutes & $25(16-42)$ & $19(14-25)$ & $17(12-28)$ & $19(16-25)$ & 0.053 & 0.0204 & - \\
\hline Use of CT angiography scan, $\%$ & 52.1 & 69.0 & 80.0 & 63.2 & 0.094 & 0.076 & - \\
\hline Door-to-needle time, minutes & $75(60-94)$ & $46(33-59)$ & $41(30-75)$ & $46(36-56)$ & 0.0001 & - & 0.4085 \\
\hline Treatment within 60 minutes door-to-needle time, $\%$ & 29.2 & 75.9 & 65.0 & 81.6 & $<0.001$ & - & 0.161 \\
\hline Onset-to-needle time, minutes & $151(127-173)$ & $130(96-176)$ & $150(94-175)$ & $124(96-176)$ & 0.217 & 0.0895 & - \\
\hline Treatment within 90 -minute onset-to-needle time, $\%$ & 2.1 & 19.0 & 25.0 & 15.8 & 0.014 & - & 0.395 \\
\hline Symptomatic intracranial hemorrhage, $\%^{\| \prime}$ & 4.2 & 1.7 & 5.0 & 0 & - & 0.361 & - \\
\hline Stroke mimic, $\%$ & 2.1 & 5.2 & 0.0 & 7.9 & - & 0.625 & - \\
\hline
\end{tabular}

$\mathrm{CT}=$ computed tomography; ICH, intracerebral hemorrhage.

Values expressed in median (interquartile range) or percentage.

*Overall refers to early and late combined.

${ }^{\dagger}$ Premodification phase, early postmodification phase, late postmodification phase.

${ }^{\ddagger}$ Premodification phase, overall postmodification phase.

${ }^{\S}$ Early postmodification phase, late postmodification phase.

"Third European Cooperative Acute Stroke Study definition of symptomatic ICH. 


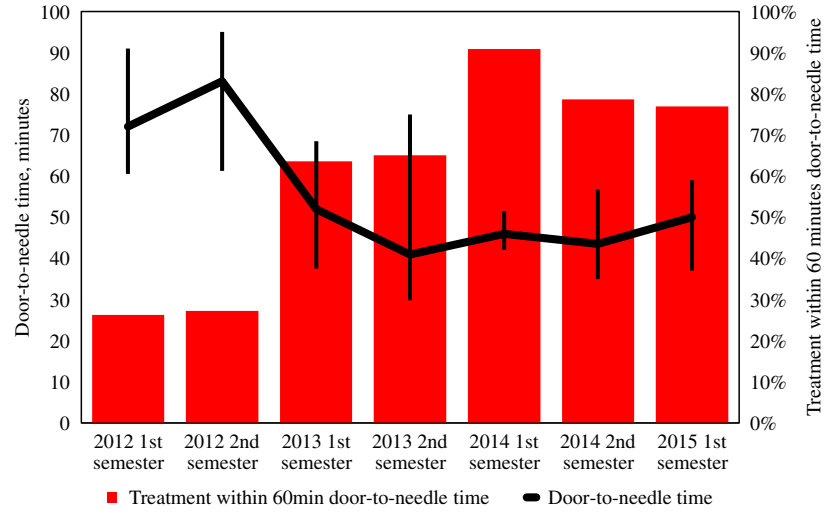

Figure 1: Proportion of patients with door-to-needle time within 60 minutes (bars) and median door-to-needle times (line) during the study period.

in May 2013 to $69.0 \%$ in July 2013 with no impact on DTN time. The largest reduction in our delays occurred between CT and alteplase bolus and was primarily attributable to not waiting for laboratory results and alteplase delivery on the CT table. Although we analyzed the impact of quality improvement efforts individually, global DTN time reduction results from an overall improvement in the system. ${ }^{7,20}$

In-hospital strokes were excluded from our study as the systems in place to manage these patients differ from those for patients coming directly to the ED. We also excluded patients transferred from other hospitals because, in these cases, the stroke team was prenotified long before patient arrival and brain imaging was often already completed at the referring site, allowing for much faster local DTN times. Patients treated in June 2013 were excluded because this was an implementation period for our new model, and we arbitrarily divided early and late postmodification phases because we presumed that positive effects from initial change-related enthusiasm were likely to be negligible beyond 6 months.

Other centers in different health care settings have also reported their strategies and successes in reducing DTN times. In Helsinki, ${ }^{6} 12$ measures were implemented over 8 years. The Melbourne Royal Hospital implemented six measures from the Helsinki model ${ }^{11}$ and found that DTN time reduction was

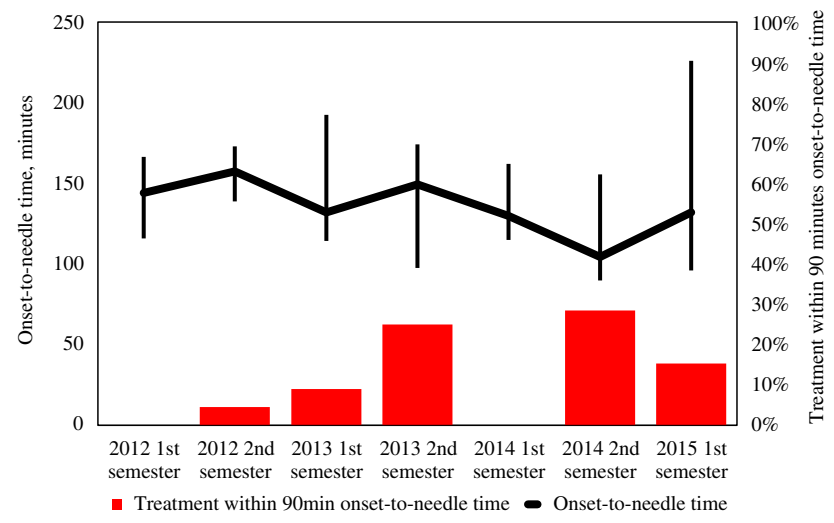

Figure 2: Proportion of patients with onset-to-needle time within 90 minutes (bars) and median onset-to-needle times (line) during the study period. achieved by maximizing preparation before patient arrival, with hospital prenotification, preacquisition of history, and preorder of tests. Most time reduction strategies were articulated in the Target: Stroke Initiative From the American Heart Association/American Stroke Association, which helped participating hospitals reduce their DTN times. ${ }^{10}$ Ten recommendations were provided to the hospitals, ${ }^{7}$ and the DTN time was reduced from 77 to 67 minutes postintervention, with improved clinical outcomes and no increase in complications.

Similarly, we found no increased risk of $\mathrm{sICH}$ and no significantly increased stroke mimic rates despite more rapid treatment, suggesting that sureness need not be sacrificed for swiftness. However, given the small sample size, functional outcome measures were not analyzed.

Our study also has other limitations. It is a single-center retrospective study that cannot eliminate confounding factors and selection and information biases. We were also unable to accurately assess the contribution of individual interventions because they were interrelated and we did not compare treatment delays between in-hours and out-of-hours. In the absence of a control group associated with a before-and-after type of study, secular trends in DTN time improvement likely exist because of increased awareness of stroke among care provider and accumulated experience and confidence in stroke care. ${ }^{6,21}$ Also, baseline radiological data including ASPECTS (Alberta Stroke Program Early CT Score) and clot burden measurements were not available, although these variables correlate with baseline NIHSS. Finally, despite laudable improvements in DTN times, it is clear that our treatment delays require even further optimization to match those achieved elsewhere.

Although we were able to meet DTN targets proposed in Canadian guidelines from 2014, ${ }^{12}$ the paramount importance and demonstrated feasibility of even faster times have led the Canadian stroke community to recently adopt new targets recommending a median DTN time of 30 minutes or less and a 90th percentile of 60 minutes. ${ }^{22}$ To achieve this ambitious but attainable target, all stroke systems must do as much as possible before patient arrival, including acquisition of patient history and demographic information for prehospital transmission to the stroke team and intravenous access insertion by EMS. This would allow preorder of blood tests and CT requests and enable CT bed preemptying. The underlying principle informing all these strategies is to permit parallel workflow and limit sequential processes in which bottlenecks are inevitable. The advent of endovascular therapy has only further reinforced the importance of streamlining hyperacute stroke care trajectories so as to safely achieve the fastest possible door-to-groin puncture and door-torecanalization times. Furthermore, once implemented, all time reduction strategies need to be continuously reevaluated and optimized to ensure not only durability but also continued safety amidst ever-faster treatment times.

\section{Disclosures}

MRK has received grants and personal fees from UCB and Sage Therapeutics that are outside the submitted work. YD has received personal fees from BMS-Pfizer, Bayer, and Novartis that are outside the submitted work. AYP has received personal fees from Medtronic, Biogen, Sanofi, and Pfizer-BMS that are outside the submitted work. BYC and AM have nothing to disclose. 


\section{Statement of Authorship}

BYC compiled and analyzed the data and drafted the manuscript. AM conceived of the study idea, compiled and analyzed the data, and reviewed the manuscript. MRK provided statistical expertise for data analysis and reviewed the manuscript. YD conceived of the study idea and reviewed the manuscript. AYP conceived of the study idea, edited the manuscript, and completed revisions.

\section{REFERENCES}

1. Adams HP Jr., del Zoppo G, Alberts MJ, et al. Guidelines for the early management of adults with ischemic stroke: a guideline from the American Heart Association/American Stroke Association Stroke Council, Clinical Cardiology Council, Cardiovascular Radiology and Intervention Council, and the Atherosclerotic Peripheral Vascular Disease and Quality of Care Outcomes in Research Interdisciplinary Working Groups: the American Academy of Neurology affirms the value of this guideline as an educational tool for neurologists. Stroke. 2007;38:1655-711.

2. Casaubon LK, Boulanger JM, Blacquiere D, et al. Canadian Stroke Best Practice Recommendations: Hyperacute Stroke Care Guidelines, update 2015. Int J Stroke. 2015;10:924-40.

3. Saver JL, Fonarow GC, Smith EE, et al. Time to treatment with intravenous tissue plasminogen activator and outcome from acute ischemic stroke. JAMA. 2013;309:2480-8.

4. Lees KR, Bluhmki E, von Kummer R, et al. Time to treatment with intravenous alteplase and outcome in stroke: an updated pooled analysis of ECASS, ATLANTIS, NINDS, and EPITHET trials. Lancet. 2010;375:1695-703.

5. Lansberg MG, Schrooten M, Bluhmki E, Thijs VN, Saver JL. Treatment time-specific number needed to treat estimates for tissue plasminogen activator therapy in acute stroke based on shifts over the entire range of the modified Rankin Scale. Stroke. 2009;40:2079-84.

6. Meretoja A, Strbian D, Mustanoja S, Tatlisumak T, Lindsberg PJ, Kaste M. Reducing in-hospital delay to 20 minutes in stroke thrombolysis. Neurology. 2012;79:306-13.

7. Fonarow GC, Smith EE, Saver JL, et al. Improving door-to-needle times in acute ischemic stroke: the design and rationale for the American Heart Association/American Stroke Association's Target: Stroke initiative. Stroke. 2011;42:2983-9.

8. Van Schaik SM, Van der Veen B, Van den Berg-Vos RM, Weinstein HC, Bosboom WM. Achieving a door-to-needle time of 25 minutes in thrombolysis for acute ischemic stroke: a quality improvement project. J Stroke Cerebrovasc Dis. 2014;23:2900-6.
9. Thortveit ET, Boe MG, Ljostad U, Mygland A, Tveiten A. Organizational changes aiming to reduce iv tPA door-toneedle time. Acta Neurol Scand. 2014;130:248-52.

10. Fonarow GC, Zhao X, Smith EE, et al. Door-to-needle times for tissue plasminogen activator administration and clinical outcomes in acute ischemic stroke before and after a quality improvement initiative. JAMA. 2014;311:1632-40.

11. Meretoja A, Weir L, Ugalde M, et al. Helsinki model cut stroke thrombolysis delays to 25 minutes in Melbourne in only 4 months. Neurology. 2013;81:1071-6.

12. Lindsay MP GG, Bayley M, Smith EE, on behalf of the Canadian Stroke Best Practices and Advisory Committee (eds). Heart and Stroke Foundation. Canadian Stroke Best Practice Recommendations. 2014.

13. Adams HP Jr., Bendixen BH, Kappelle LJ, et al. Classification of subtype of acute ischemic stroke. Definitions for use in a multicenter clinical trial. TOAST. Trial of Org 10172 in Acute Stroke Treatment. Stroke. 1993;24:35-41.

14. Hacke W, Kaste M, Bluhmki E, Brozman M, Dávalos A, et al. ECASS Investigators. Thrombolysis with alteplase 3 to 4.5 hours after acute ischemic stroke. N Engl J Med. 2008;359: 1317-29.

15. Price CI, Clement F, Gray J, Donaldson C, Ford GA. Systematic review of stroke thrombolysis service configuration. Expert Rev Neurother. 2009;9:211-33.

16. Gomez CR, Malkoff MD, Sauer CM, Tulyapronchote R, Burch CM, Banet GA. Code stroke. An attempt to shorten inhospital therapeutic delays. Stroke. 1994;25:1920-3.

17. Zweifler RM, Drinkard R, Cunningham S, Brody ML, Rothrock JF. Implementation of a stroke code system in Mobile, Alabama. Diagnostic and therapeutic yield. Stroke. 1997;28:981-3.

18. Belvis R, Cocho D, Marti-Fabregas J, et al. Benefits of a prehospital stroke code system. Feasibility and efficacy in the first year of clinical practice in Barcelona, Spain. Cerebrovasc Dis. 2005;19: 96-101.

19. Lin CB, Peterson ED, Smith EE, et al. Emergency medical service hospital prenotification is associated with improved evaluation and treatment of acute ischemic stroke. Circ Cardiovasc Qual Outcomes. 2012;5:514-22.

20. Kohrmann M, Schellinger PD, Breuer L, et al. Avoiding in hospital delays and eliminating the three-hour effect in thrombolysis for stroke. Int J Stroke. 2011;6:493-7.

21. Koennecke HC, Nohr R, Leistner S, Marx P. Intravenous tPA for ischemic stroke team performance over time, safety, and efficacy in a single-center, 2-year experience. Stroke. 2001;32: 1074-8.

22. Kamal N, Benavente O, Boyle $\mathrm{K}$, et al. Good is not good enough: the benchmark stroke door-to-needle time should be 30 minutes. Can J Neurol Sci. 2014;41:694-6. 